Marquette University

e-Publications@Marquette

Biomedical Engineering Faculty Research and

Publications

Biomedical Engineering, Department of

9-1-2012

\title{
Creep Evaluation of (Orthotic) Cast Materials During Simulated Clubfoot Correction
}

T. L. Cohen

Marquette University

H. Altiok

Sergey Tarima

P.A. Smith

Gerald F. Harris

Marquette University, gerald.harris@marquette.edu

Accepted version. Published as part of the proceedings of the conference, 2012 Annual International Conference of the IEEE Engineering in Medicine and Biology Society (EMBC), 2012: 3352-3355. DOI:

(C) 2012 Institute of Electrical and Electronics Engineers (IEEE). Used with permission. 


\title{
Creep Evaluation of (Orthotic) Cast Materials During Simulated Clubfoot Correction
}

\author{
Tamara L. Cohen \\ Orthopaedic Rehabilitation and Engineering Research Center (OREC), \\ Marquette University/Medical College of Wisconsin, \\ Milwaukee, WI \\ Haluk Altiok \\ Shriners Hospitals for Children, Chicago, IL \\ Sergey Tarima \\ Department of Biostatistics, Medical College of Wisconsin, \\ Milwaukee, WI \\ Peter A. Smith \\ Shriners Hospitals for Children, Chicago, IL \\ Gerald F. Harris \\ Orthopaedic Rehabilitation and Engineering Research Center (OREC), \\ Marquette University/Medical College of Wisconsin, \\ Milwaukee, WI
}


Abstract: The Ponseti method is a widely accepted and highly successful conservative treatment of pediatric clubfoot that relies on weekly manipulations and cast applications. However, the material behavior of the cast in the Ponseti technique has not been investigated. The current study sought to characterize the ability of two standard casting materials to maintain the Ponseti corrected foot position by evaluating creep response. A dynamic cast testing device (DCTD) was built to simulate a typical pediatric clubfoot. Semi-rigid fiberglass and rigid fiberglass casting materials were applied to the device, and the rotational creep was measured at various constant torques. The movement was measured using a 3D motion capture system. A 2-way ANOVA was performed on the creep displacement data at a significance level of 0.05 . Among cast materials, the rotational creep displacement was found to be significantly different ( $p$-values $\ll 0.001$ ). The most creep displacement occurs in the semi-rigid fiberglass (approximately 1.0 degrees), then the rigid fiberglass (approximately 0.4 degrees). There was no effect of torque magnitude on the creep displacement. All materials maintained the corrected position with minimal change in position over time.

\section{SECTION I.}

\section{Introduction}

Idiopathic clubfoot is a congenital deformity of the lower extremity, with a prevalence of 1 to 6 in 1000 births. ${ }^{1,2}$ The Ponseti method is a mainstay conservative clubfoot treatment that relies on manipulation and casting of the foot done weekly.1,2,3,4,5 Casting with plaster-of-Paris has been the historical standard for clubfoot immobilization since it was introduced by Guerin.1,4,6 Traditionally, plaster-of-Paris has been long praised for its moldability and patient comfort for serial casting purposes. On the other hand, it can be heavy, takes a long time to dry completely, and requires soaking for several hours or a cast saw to remove it, risking skin injury. Alternative cast materials have been introduced for use in clubfoot treatment, including rigid (RF) and semi-rigid fiberglass (SRF). Results from previous clinical studies have indicated the potential success of the Ponseti method with the use of materials other than plaster-of-Paris. ${ }^{6,7,8,9}$ Material selection could affect not only the comfort level of the patient but also the efficacy of the technique.

Over the last few decades, studies have been conducted to determine mechanical properties of different cast materials, as well as to identify the advantages of using one material over another.8,10,11,12,13,14 A variety of metrics have been investigated to define material properties, such as stiffness, ultimate strength, and yield strength, or the point at which the material will begin to plastically deform, based on tests performed in compression, tension, and bending. One limitation of these studies is that these tests are based on models that do not adequately represent the clinical application. Corrective casts used with the Ponseti method are applied across a joint and are subjected to complex loads exceeding simple compression. Nor do these previous models account for the permanent 
cast deformation that occurs under prolonged low level loading conditions, or creep. An improved model is required to better simulate the clinical application and to address the mechanical behavior of the limb-cast composite. ${ }^{8}$

The objectives addressed in this study are 1) to characterize the ability of SRF and RF casting materials to maintain the Ponseti corrected foot position and 2) to determine the sensitivity of the casts to creep under corrective joint load conditions. In the current study, creep displacement is evaluated through application of an experimental foot model tested with the casting materials at two constant torque conditions.

\section{SECTION II.}

\section{Methods}

\section{A. Device Design}

A dynamic cast testing device (DCTD) was built to simulate pediatric clubfoot correction with casting. A single axis of correction was evaluated in order to isolate the cast creep characteristics. The anatomic segments were constructed from 1 inch Schedule 40 PVC piping. The axis of correction consisted of a stainless steel hinge (1/4 - inch diameter pin, 3-11/32 inch leaf length) that allowed the distal (foot) segment to rotate about an axis parallel to the proximal (shank) segment. Knee and thigh segments made from PVC piping were also attached to the shank segment in order to simulate a long leg cast. The DCTD was anchored to a fixed platform.

\section{B. Torque Acquisition}

A constant torque (low or high) was applied to the DCTD through a weighted cable. The torque values were determined with the use of the Ponseti teaching model (MD Orthopaedics; Wayland, IA). Two experienced orthopaedic surgeons applied a corrective torque sufficient to abduct the foot to neutral. A spring scale was connected to the model and the Ponseti technique was applied by each surgeon. A total of seven correction trials were performed. The resulting torque was $0.62 \mathrm{Nm} \pm 0.12 \mathrm{Nm}$. The minimum and maximum applied corrective torques, $0.44 \mathrm{Nm}$ and $0.75 \mathrm{~nm}$, were used in the subsequent creep evaluation test. 
NOT THE PUBLISHED VERSION; this is the author's final, peer-reviewed manuscript. The published version may be accessed by following the link in the citation at the bottom of the page.

\section{Creep Test Protocol}

Vendor instructions were followed during application of the two cast materials: rigid fiberglass ( $3 \mathrm{M}^{\mathrm{TM}}$, Parsippany, $\left.\mathrm{NJ}\right)$, and semi-rigid fiberglass ( $3 \mathrm{M}^{\mathrm{TM}}$, Parsippany, $\left.\mathrm{NJ}\right)$. A protective latex sleeve was located about the hinge joint. The device was held in neutral alignment with a fixture during the cast set-up and setting time. A single layer of cast padding $\left(3 \mathrm{M}^{\mathrm{TM}}\right.$, Parsippany, $\left.\mathrm{NJ}\right)$ was wrapped around the device with $50 \%$ overlap.

The DCTD was casted with the materials according to vendor specifications. The RF and SRF were dipped in room temperature water and applied without wringing. Time was marked at the initiation of casting to monitor the setting time and data acquisition intervals. The wet roll was then applied to the DCTD. Four layers of material were wound around the device, with $50 \%$ overlap and along the same length as the padding. Molding and contouring was performed to ensure a proper fit and adhesion.

The positions of two triads of 7-mm diameter IRED (Infra-Red-light-EmittingDiode) markers, placed at each end of the device (Fig. 1), were monitored by Optotrak System cameras (Northern Digital, Inc.) during testing. Five trials were completed per cast material for each torque for a total of 20 trials in the study. Data acquisition began four minutes after the start of cast application. Three 10-minute intervals of time were recorded at a $1 \mathrm{~Hz}$ sampling frequency. Interval 1 was recorded from minutes 4 to 14. Interval 2 was recorded from minutes 18 to 28 . Interval 3 was recorded from minutes 60 to 70.

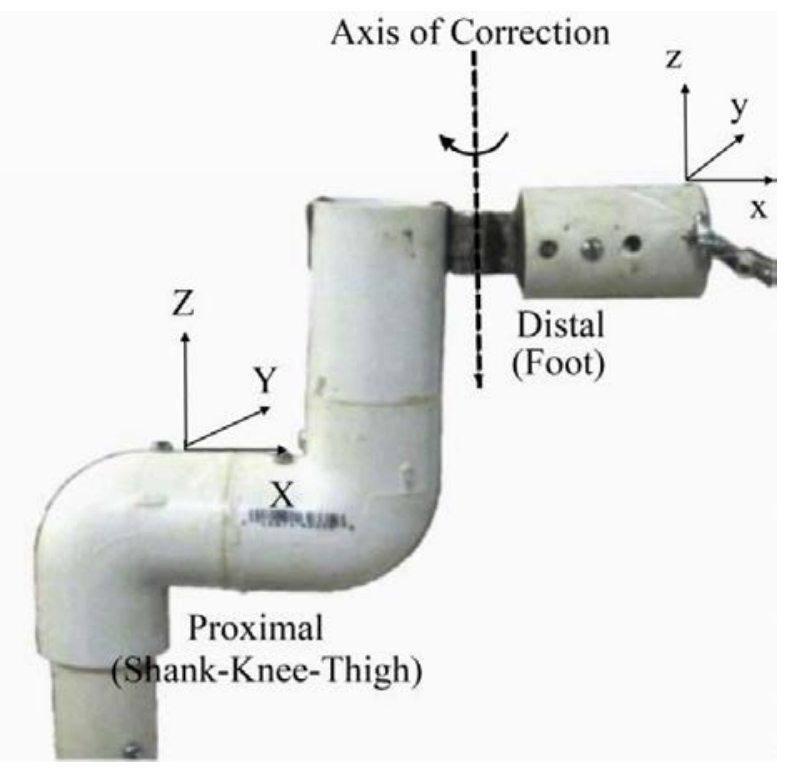

Figure 1: Dynamic Cast Testing Device (DCTD).

2012 Annual International Conference of the IEEE Engineering in Medicine and Biology Society (EMBC), (2012): pg. 3352-3355. DOI. This article is (C) Institute of Electrical and Electronics Engineers (IEEE) and permission has been granted for this version to appear in ePublications@Marquette. Institute of Electrical and Electronics Engineers (IEEE) does not grant permission for this article to be further copied/distributed or hosted elsewhere without the express permission from Institute of Electrical and Electronics Engineers (IEEE). 
Coordinate systems for the foot and shank-thigh segments were calculated with the z-axis pointed inferiorly, aligned with the hinge axis, the $y$-axis pointed laterally, and the $x$ axis pointed anteriorly (Fig. 1).

\section{Mathematical and Statistical Analysis}

The motion data from each trial were analyzed in Matlab to compute segment translation and rotation throughout testing. The Euler angle sequence, Z-Y-X, was used to describe the relative rotation of the distal (foot) segment to the proximal (shank-thigh) segment. Angular creep displacement, $\Delta \theta(t)$, was calculated as:

$$
\Delta \theta(\mathrm{t})=\theta(\mathrm{t})-\theta_{0},(1)
$$

where $t$ is time in seconds, $\theta(t)$ is the angle in degrees at time $t$, and $\theta_{0}$ is the initial angle in degrees recorded at $t_{0}$. This measurement was calculated for the total trial length and per interval. Percent of total rotation was also determined for each interval. The average creep and standard deviation for the five trials in each condition were computed. A Shapiro-Wilk test performed on the data concluded normal distribution; then the data was evaluated using a two-way ANOVA for the factors cast material and torque. Significance was defined as $\mathrm{p}<0.05$.

Curve fitting was performed on the averaged creep displacement data using a least absolute residuals formulation. Observed and predicted values were calculated from the best-fit model at times of 20 minutes, 72 hours, and 7 days to conform to clinical standards.

\section{SECTION III.}

\section{Results}

The resultant translational displacement of the system was calculated to be less than $0.05 \mathrm{~mm}$ for each of the cast materials under either torque. Rotational creep displacement about the axis of the hinge (z-axis) is illustrated in Fig. 2 and corresponds with forefoot adduction. 

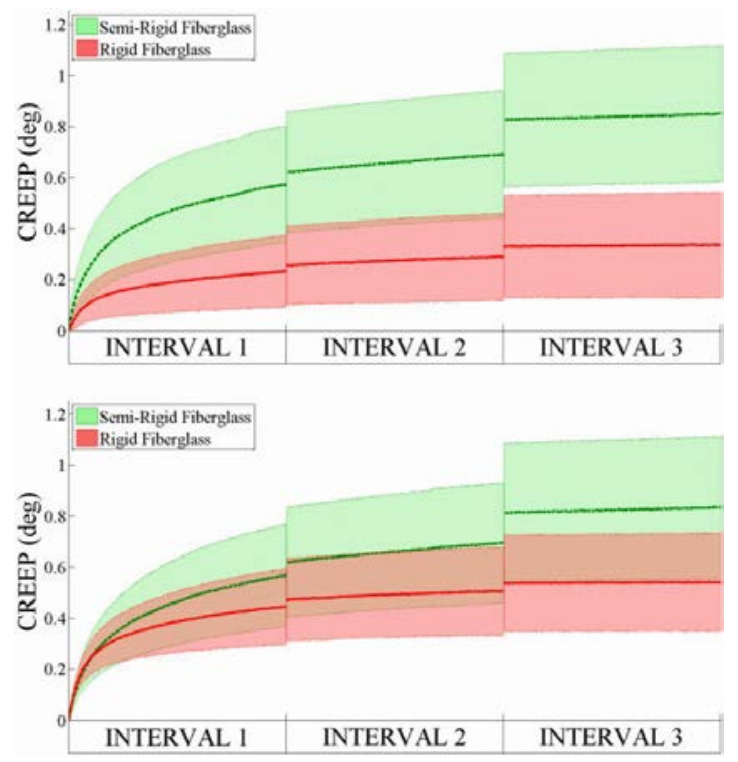

Figure 2: Average and standard deviation of creep displacement for SRF and RF under A) low and B) high torques. Interval 1: 4-14 minutes; Interval 2: 18-28 minutes; Interval 3: 60-70 minutes.

The average creep displacement was calculated for the entire trial length, as well as per interval. The results can be seen in table 1 . The greatest amount of creep was produced when using POP. The first ten minute interval of testing experienced the most creep, accruing over $65 \%$ of the total creep. Material type was found to significantly affect the total creep ( $\mathrm{p}<<0.001)$, while the effect of torque was determined to be negligible ( $p>0.05$ ). This result was also seen when examining the creep displacement occurring at the end of time interval $1(p=0.01)$.

TABLE I Average Creep Displacement

\begin{tabular}{lllll} 
& \multicolumn{2}{c}{ Semi-Rigid Fiberglass } & \multicolumn{2}{c}{ Rigid Fiberglass } \\
& Low Torque & High Torque & Low Torque & High Torque \\
Interval 1 Creep (deg) & 0.6 & 0.6 & 0.2 & 0.4 \\
& \pm 0.2 & \pm 0.2 & \pm 0.1 & \pm 0.2 \\
Total Creep (deg)* $^{*}$ & 0.9 & 0.8 & 0.3 & 0.5 \\
& \pm 0.3 & \pm 0.3 & \pm 0.2 & \pm 0.2
\end{tabular}

Mathematical models of the creep behavior of each cast material are presented in Fig. 3. The response of all three cast materials were best described using a power equation with two terms,

$$
C(t)=a \times t^{b}+d,(2)
$$


where $C(t)$ is the curve-fit creep displacement response, $t$ is the time (in seconds), and $a, b$, and $d$ are coefficients. Predicted creep displacement values are presented in table 2 . From the first 20 minutes of drying and 7days, the SRF displacement increases by $93 \%$ and $82 \%$, under low and high torques, respectively, while the RF displacement increases by $83 \%$ and $35 \%$, under low and high torques, respectively. Increases of $10 \%$ and $7.5 \%$ for the low and high torque trials of SRF, and increases of $8.3 \%$ and $1.5 \%$ for the low and high torque trials of RF, are seen between 72 hours and 7 days.
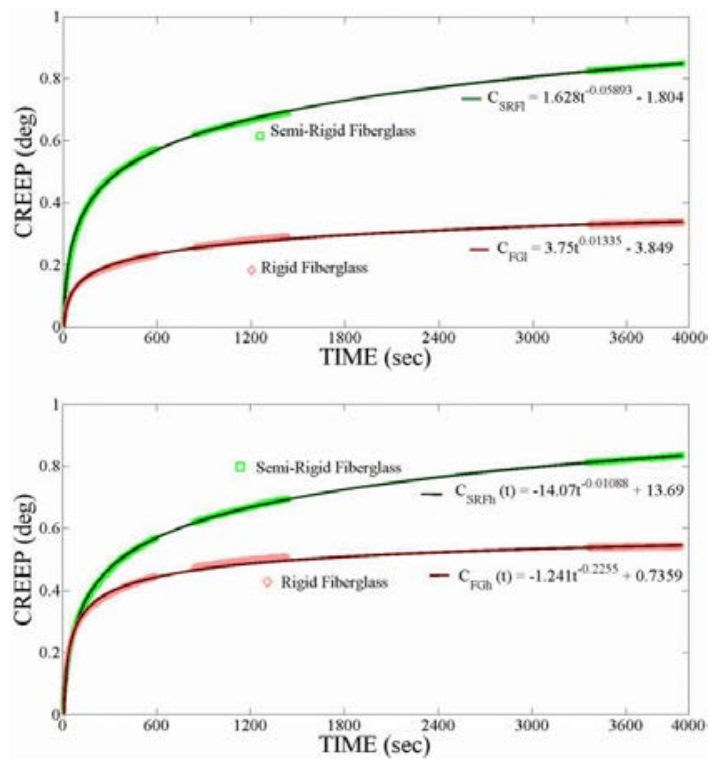

Figure 3: Data and curve-fits of average rotational creep displacement of SRF and RF under A) low torque and B) high torque.

\section{SECTION IV.}

\section{Discussion}

The results presented in this study represent the creep displacement experienced by 2 cast materials under constant torques, based on clinical conditions of clubfoot correction. The study resulted in small amounts of creep for both cast materials, with a maximum of only 1 degree. The findings indicate that more creep displacement is experienced by the semi-rigid fiberglass (SRF) than the rigid fiberglass (RF), regardless of the torque level. Relevant outcomes of this experiment include the creep displacement dependence on cast material and independence from torque. Clinically, this would indicate that severity of deformity will not affect the creep of the cast material. 
This experiment models the rotational displacement response and the findings do correspond with those of studies investigating cast rigidity and compliance. For example, the results of this study agree with those of pressure-volume and skin pressure studies conducted by Deshpande et al. and Davids et al., as those studies showed that SRF was more compliant than RF. ${ }^{10,11}$ In addition, their findings suggest that RF most rigid of all cast materials tested they tested Results in these studies were determined by gauging the pressure change when infusing measured volumes of fluid into bladders that surrounded by cast material. Discrepancies with other studies' results could be attributed to the complex combination of motion, padding, and/or multilayering effect that were based on the standard clinical procedure (Ponseti method) that was applied.

In addition, many of the studies examining mechanical properties of these cast materials looked at the material properties after the recommended curing time for weight bearing and at higher loads. As a result, their conclusions are of the ultimate and yield behaviors of the materials at a specific water content percentage. In the current study, an internal torque, applicable to joint stiffness, supplied the driving force on the cast after the recommended setting time, which is clinically relevant to the conservative clubfoot treatment procedure. The forces being applied to the cast during treatment are significantly lower than those seen during yield, as defined by the definition of the creep phenomena.

TABLE II Predicted Creep Displacement

\begin{tabular}{lllll} 
& \multicolumn{2}{c}{ Semi-Rigid Fiberglass } & \multicolumn{2}{c}{ Rigid Fiberglass } \\
& Low Torque & High Torque & Low Torque & High Torque \\
20 minutes & 0.64 & 0.63 & 0.26 & 0.47 \\
72 hours & 1.59 & 1.41 & 0.58 & 0.66 \\
7 days & 1.76 & 1.52 & 0.63 & 0.67
\end{tabular}

Furthermore, this study shows the behavior of the material as it undergoes water content changes. Berman et al. found that water content had a minimal effect on the strength of synthetic cast as it had reached $75 \%$ of its 5 day strength after a curing time of 1 hour. ${ }^{12}$ In the current study, the creep displacement models predict that about $50 \%$ of the 7 day displacement for the SRF under either load, about $50 \%$ of it for the RF under low torque and about $75 \%$ of it for the RF under the high torque is reached at 1 hour. In addition, the creep may plateau as the torque produced by the joint tissues relaxes over this time period. 
A preliminary analysis of the creep strain (creep displacement $(\Delta \theta(\mathrm{t}))$ divided by initial angle $\left.\left(\theta_{0}\right)\right)$ showed diverging strain vs. time curves for the rigid fiberglass. A preliminary inspection of the creep compliance (strain at time $t$ divided by the stress applied) showed two distinct creep compliance vs. time curves, indicating nonlinearity. This analysis will be continued for both cast materials in future work.

Studies examining the use of different orthopaedic casting materials have resulted in unclear conclusions as to which material is best for clubfoot treatment based on patient satisfaction and efficacy. ${ }^{8}$ Zmurko et al. found that even though his tests showed that SRF was best used with non-rigid immobilization from three-point bending and diametrical compression tests, one of the authors had been using this material in the correction of clubfoot and metatarsus adductus and found it to be sufficiently rigid for the procedure. Pittner et al. found that in clinical trials, the clubfeet corrected with either plaster of Paris or SRF both resulted in a 95\% overall correction rate with the addition of percutaneous tendoachilles lengthening. However, those feet treated with SRF casts had statistically significant lower Dimeglio-Bensahel scores at the completion of non-operative manipulation. Patient satisfaction in terms of convenience, cast weight, and cast durability was higher for the semi-rigid fiberglass. In a study comparing parent satisfaction with plaster of Paris and SRF used during serial casting, Coss et al. found that parents preferred the SRF based on its ease of removal, durability, and performance. ${ }^{9}$ In their study though, the authors did not correlate each cast material in regard to their efficacy. Similarly, Brewster et al. ${ }^{7}$ using SRF and Kin-Wah Ng et al. ${ }^{15}$ using fiberglass material, published their favorable clinical results.

Some limitations are present in this examination. This study models rigid bodies that are connected by a single, revolute hinge joint. While the ankle-subtalar complex is not a simple revolute joint, the model represents the second, most prominent phase of clubfoot correction by addressing the transverse plane adduction. In addition, the cast materials' responses to the simulated joint stiffness may be a function of the number of layers used in the construction of the cast. The effectiveness of the cast material may depend on the surgeon`s molding skill. The moldability of the cast material and its significance on the ability to apply the cast material and its influence on the efficacy of clubfoot treatment is not addressed in this model. To date, there have been no studies that specifically address moldability.

In future work, we plan to investigate further the viscoelastic linearity of these materials, as well as analyze and compare the behavior of plaster of Paris. In addition, the tissue mechanics of the clubfoot ankle ligaments will be explored to assess the mechanical 
NOT THE PUBLISHED VERSION; this is the author's final, peer-reviewed manuscript. The published version may be accessed by following the link in the citation at the bottom of the page.

response to treatment. A better understanding of the mechanics of clubfoot correction will aid in future innovations of clubfoot care.

\section{Acknowledgment}

T.L.C thanks Dr. Mei Wang, Ms. Linda McGrady, Mr. Joseph Krzak, Mr. Adam Graf, and Dr. Steven Abramowitch for their assistance and helpful input.

\section{References}

1M. B. Dobbs and C. A. Gurnett, "Update on clubfoot: etiology and treatment," Clinical Orthopaedics \& Related Research, Vol. 467, pp. 1146-53, May 2009.

2J. A. Morcuende, "Congenital idiopathic clubfoot: prevention of late deformity and disability by conservative treatment with the Ponseti technique," Pediatric Annals, Vol. 35, pp. 128-30, 132-6, Feb 2006.

3B. D. Roye, J. Hyman, and D. P. Roye, Jr, "Congenital Idiopathic Talipes Equinovarus," Pediatrics in Review, Vol. 25, pp. 124-130, April 1, 2004.

${ }^{4}$ I. V. Ponseti and J. Campos, "Observations on pathogenesis and treatment of congenital clubfoot," Clinical Orthopaedics \& Related Research, Vol. 84, pp. 50-60, May 1972.

${ }^{5}$ S. J. Laaveg and I. V. Ponseti, "Long-term results of treatment of congenital club foot," Journal of Bone \& Joint Surgery American, Vol. 62, pp. 23-31, Jan 1980.

${ }^{6}$ D. E. Pittner, K. E. Klingele, and A. C. Beebe, "Treatment of clubfoot with the Ponseti method: a comparison of casting materials," Journal of Pediatric Orthopedics, Vol. 28, pp. 250-3, Mar 2008.

${ }^{7}$ M. B. S. Brewster, M. Gupta, G. T. R. Pattison, and I. D. Dunn-van der Ploeg, "Ponseti casting: A New Soft Option," Journal of Bone \& Joint Surgery British, Vol. 90-B, pp. 1512-1515, November 1, 2008.

8M. G. Zmurko, S. M. Belkoff, and J. E. Herzenberg, "Mechanical evaluation of a soft cast material," Orthopedics, Vol. 20, pp. 693-8, Aug 1997.

${ }^{9}$ H. S. Coss and W. L. Hennrikus, "Parent satisfaction comparing two bandage materials used during serial casting in infants," Foot \& Ankle International, Vol. 17, pp. 483-6, Aug 1996.

10J. R. Davids, S. L. Frick, E. Skewes, and D. W. Blackhurst, "Skin Surface Pressure Beneath an Above-theKnee Cast: Plaster Casts Compared with Fiberglass Casts," Journal of Bone \& Joint Surgery American, Vol. 79, pp. 565-9, April 1, 1997.

${ }^{11} \mathrm{~S}$. V. Deshpande, "An experimental study of pressure-volume dynamics of casting materials," Injury, Vol. 36, pp. 1067-74, Sep 2005.

${ }^{12} \mathrm{~A}$. T. Berman and B. G. Parks, "A comparison of the mechanical properties of fiberglass cast materials and their clinical relevance," Journal of Orthopaedic Trauma, Vol. 4, pp. 85-92, 1990.

${ }^{13}$ D. J. Callahan, D. J. Carney, N. Daddario, and N. E. Walter, "A comparative study of synthetic cast material strength," Orthopedics, Vol. 9, pp. 679-81, May 1986.

${ }^{14}$ W. M. Mihalko, A. J. Beaudoin, and W. R. Krause, "Mechanical Properties and Material Characteristics of Orthopaedic Casting Material," Journal of Orthopaedic Trauma, Vol. 3, pp. 57-63, 1989. 
NOT THE PUBLISHED VERSION; this is the author's final, peer-reviewed manuscript. The published version may be accessed by following the link in the citation at the bottom of the page.

${ }^{15}$ B. K. Ng, T. P. Lam, and J. C. Cheng, "Treatment of severe clubfoot with manipulation using synthetic cast material and a foam-casting platform: a preliminary report," Journal of Pediatric Orthopaedics B, Vol. 19, pp. 164-70, Mar 2010.

2012 Annual International Conference of the IEEE Engineering in Medicine and Biology Society (EMBC), (2012): pg. 3352-3355. DOI. This article is (C) Institute of Electrical and Electronics Engineers (IEEE) and permission has been granted for this version to appear in e-

Publications@Marquette. Institute of Electrical and Electronics Engineers (IEEE) does not grant permission for this article to be further copied/distributed or hosted elsewhere without the express permission from Institute of Electrical and Electronics Engineers (IEEE). 